\title{
Correction to: Sequential anti-CD19, 22, and 20 autologous chimeric antigen receptor T-cell (CAR-T) treatments of a child with relapsed refractory Burkitt lymphoma: a case report and literature review
}

Juan $\mathrm{Du}^{1} \cdot$ Yonghong Zhang ${ }^{1}$

Published online: 25 May 2020

○) Springer-Verlag GmbH Germany, part of Springer Nature 2020

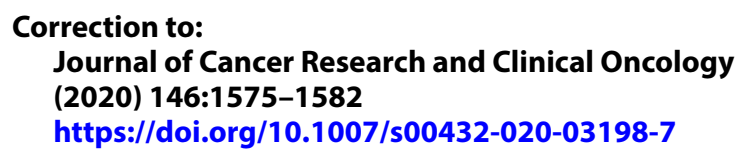

In the original article published, the first author's affiliation is incorrect. The correct affiliation of the author Juan Du is Children's Lymphoma Ward, Beijing Boren Hospital, Beijing 100070, China.

Publisher's Note Springer Nature remains neutral with regard to jurisdictional claims in published maps and institutional affiliations.

The original article can be found online at https://doi.org/10.1007/ s00432-020-03198-7.

Yonghong Zhang

hyzhang58@126.com

1 Children's Lymphoma Ward, Beijing Boren Hospital,

Beijing 100070, China 